\title{
Okul Öncesi Dönem Çocuklarının Öğrenme Stillerinin İncelenmesi*
}

\author{
Analyzing the Learning Styles of Preschool Children
}

\author{
Gökhan GÜNEŞ**, Semra ERKAN***
}

Öz: Bu araştırmada, okul öncesi grubu çocuklarının öğrenme stillerinin belirlenip, cinsiyet değişkenine göre incelenmesi amaçlanmıştır. Bu amaç doğrultusunda, çalışmanın örneklemini oluşturan 128 çocuğa, Güneş (2014) tarafindan geliştirilen Çocuklar İçin Öğrenme Stilleri İndeksi (ÇïÖSİ) uygulanmıştır. Elde edilen veriler betimsel olarak incelenmiştir ve cinsiyet değişkeninin gruplar arasında anlamlı farka neden olup olmadığının anlaşılması için sonuçlar üzerinde bağımsız gruplar t-Testi uygulanmıştır. Yapılan araştırmada genel olarak çocukların aktif/sezgisel/görsel ve sıralı (analitik) öğreniciler olduğu bulunmuştur. Çocukların öğrenme stillerinden aktif ve görsel alt boyutlarında yoğunlaştığı, bununla beraber algısal/sezgisel ve bütünsel/sıralı alt boyutlarında yer alan her iki öğrenme stilinin de birbirine çok yakın olduğu söylenebilir. ÇiöSİ sonuçlarına göre çocukların genel olarak aktif/sezgisel/görsel ve sıralı (analitik) öğreniciler olduğu bulunmuştur. ÇiÖSİ üzerinde yapılan betimsel istatistik sonuçlarına göre aktif öğrenme \%65 ve görsel öğrenme \%67 ile en baskın öğrenme stilleri olarak belirlenmiştir. Bunun yanı sıra sezgisel-algısal ve sıralı-bütünsel öğrenmelerin daha dengeli oranda kullanıldıkları hesaplanmıştır. Yapılan t-Testi sonuçlarına göre, kızların yansıtıcı ve sıralı (analitik) öğrenme tercihlerinin erkeklere göre istatistiksel olarak anlamlı şekilde farklılık gösterdiği sonucuna ulaşılmıştır. ÇïÖSİ'nin okul öncesi dönemde çocuğu tanıma ve değerlendirmede kullanılabilecek bir ölçüm aracı olduğu görülmektedir. Araştırma sonuçlarından hareketle, öğretmenlerin öğrenmenin etkililiği ve maksimum öğrenme kapasitesine ulaşma yolunda çocukların çok ve az tercih ettikleri öğrenme stillerinin geliştirilmesine firsat tanıyacak öğrenme ortamlarını ve etkinlerini planlamaları önerilmektedir.

Anahtar Kelimeler: Okul öncesi dönem, öğrenme stilleri, cinsiyet değişkeni

\begin{abstract}
The purpose of this the learning styles of preschool children and understand the effect of gender factor on learning styles. The research is carried out with 128 children. To determine the learning styles of children the Index of Learning Styles for Children (ILSC) which was developed by Güneş (2014) has been used. Descriptive analyses used for determining the learning styles of children. Moreover, t-Test used for understanding the effect of gender on learning style. According to ILSC results, in general children are active/intuitive/visual and analytical/sequential/consecutive learners. As a result of descriptive analyses, active (65\%) and visual (67\%) learning styles are dominant learning styles. On the other hand, intuitive-sensing and sequential-global learning styles are used by more balanced rather than visual and active learning styles. According to t-Test results there is a statistically significant difference between girls and boys on reflective and sequential learning styles on behalf of girls. It is seen that ILSC can be used for a recognition and evaluation instrument for preschool children. It can be recommended from the results of the study, teachers can arrange the learning environments and planning activities according to children's much and less preferred learning styles for reaching maximum learning capacity.

Keywords: Preschool children, learning styles, gender variable
\end{abstract}

\section{Giriş}

Kişilik kuramcılarından Adler insanın sosyal ilgi ile doğduğunu belirterek, bireyselleşmesinde kişisel ilgi alanlarının, duygu ve düşüncelerinin etkili olduğunu savunmaktadır. Adler'e göre, öğrenme düşünceler yoluyla, kişilik ise düşünce biçimleri ile oluşmaktadır (Passer ve Smith,

\footnotetext{
*Bu çalışma Prof. Dr. Semra ERKAN danışmanlığında Gökhan GÜNEŞ tarafından hazırlanan "Çocukların epistemolojik görüşlerinin ve öğrenme stillerinin Öklidyen Geometrisinde modellenmesi” isimli doktora tezinin bir bölümünden üretilmiştir.

**Yrd. Doç. Dr., Hakkari Üniversitesi, Eğitim Fakültesi, Hakkari-Türkiye, e-posta:gokhangunes44@gmail.com

***Prof. Dr., Hacettepe Üniversitesi, Eğitim Fakültesi, Ankara-Türkiye, e-posta:nsemraerkan@gmail.com
} 
2008). Diğer bir kuramcı olan Jung ise eylemlerimizin ve öğrenmelerimizin farklı ve kompleks yapılı kaynaklarının olduğunu belirterek, kişilik tipolojilerinden bahsetmiştir (Wilson, Robeck ve Michael, 1974). Jung (1927) kişilik tiplerinin öğrenme stilleri ile bağlantılı olduğunu ve kişilik tiplemelerini en temel hatları ile içe dönük ve dışa dönük sınıflara ayrıldığını belirterek, düşünme biçimlerinin de benzer bir yapıda olduğunu iddia etmiştir (Akt., Passer ve Smith, 2008). Öğrenme üzerine yapılan çalışmalara dayanarak, bireysel bilgi yapılandırılmasında kişilik özelliklerinin ve bu özelliklerin etkilediği öğrenme stillerinin etkili olduğunu söyleyebiliriz. Bu söylemi, Dunn'ın öğrenme stillerini, her bir öğrencinin yeni ve zor bilgiyi öğrenmeye hazırlanırken, öğrenirken ve hatırlarken farklı ve kendilerine özgü yollar kullanması tanımı destekler niteliktedir (Dunn, Griggs, Olson ve Beasley, 1995).

İnsanların düşüncelerini ve davranışlarını düzenleme yetenekleri birbirlerinden farklıdır ve bu bireysel farklılıklar kişisel seçimlerin belirlenmesinde etkilidir (Miyake ve Friedman, 2012). Bireysel farklılıklar sadece zekâ, bilişsel stiller ve davranışlar üzerinde değil aynı zamanda öğrenme ve öğretme süreçlerinde de önemli bir rol oynamaktadır (Jonassen ve Grabowski, 1993). Bireysel farklılıkların öğrenme üzerine etkilerinden hareketle, her bireyin kendine özgü öğrenme stratejileri ve stilleri olduğu bilinmektedir (Dunn, 1986; Dunn ve Dunn, 1992, Felder ve Silverman, 1988; Gregorc, 1979; Kolb, 1976). Her birey için özelleşen öğrenme stilleri ve modelleri alanyazında farklı şekillerde tanımlanmaktadır. Dunn, Griggs, Olson ve Beasley (1995) öğrenme stilini, her bir öğrencinin yeni ve zor bilgiyi öğrenmeye hazırlanırken, öğrenirken ve hatırlarken farklı ve kendilerine özgü yollar kullanması olarak tanımlamaktadır. Gregorc (1979) ise öğrenme stillerini, bireylerin yetenekleri, dünyayla ilgili düşünceleri ve nasıl öğrendikleri hakkında ipucu veren kendine özgü ve gözlemlenebilir davranışlar olarak belirtmektedir. Grasha' ya (1996) göre, öğrenme stilleri, öğrencinin bilgi edinme, arkadaşları ve öğretmeni ile etkileşim ve öğrenme tecrübelerine katılımında etkili olan kişisel özellikleridir. Kolb (1984) ise öğrenme stili modelinde, öğrenmeyi, bilginin üretiminden deneyime dönüştürülme süreci olarak kabul etmekte ve öğrenme stillerini, değiştiren, özümseyen, yerleştiren ve ayrıştıran öğrenme kavramlarının oluşturduğu çember (cycle) üzerinden tanımlamaktadır. Keefe (1979) öğrenme stillerini öğrenenlerin algıları, etkileşimleri ve öğrenme ortamlarında verdikleri tepkileri gösteren, bilişsel duyuşsal ve psikolojik davranışlar olarak kabul etmektedir. Fleming (2001) bireysel özellikler kapsamında bilginin alınması, organizasyonu ve bilgi hakkındaki düşünceleri öğrenme stilleri olarak tanımlamıştır. Felder ve Brent (2005) ise öğrenme stillerini kısaca bilginin alınma ve işlenme süreci olarak değerlendirmektedir. Öğrenme stilleri alanında yapılan çalışmalar dikkate alındığında (Balat, Bilgin ve Özdemir, 2012; Dunn ve Dunn, 1992, Felder ve Silverman, 1988; Fleming, 2011; Gregorc, 1979; Kolb, 1976; Leite, Svinicki ve Shi, 2010) öğrenme stillerinin standart olmadığı, buna karş1 öğrenme stillerinin bilişsel (Gregorc, 1979; Kolbve Kolb, 2005), duyuşsal ve fizyolojik (Dunn ve Dunn, 1992) boyutlarıyla ele alındığı söylenebilir. Duyusal modellere örnek olarak Fleming' in (2001), görsel (V-visual), işitesel (A-aural), harekete dayalı (K-kinesthetic) ve okuma-yazma (R-reading \& writing) becerilerini ölçmeye çalıştı̆̆ VARK modeli verilebilir. Bunun yanı sıra, öğrenme stilleri ölçüm araçları (Gregorc, 1979; Felder ve Silverman, 1988; Dunn ve Dunn, 1992, Kolb ve Kolb, 2005) gelişim düzeyi ve kültürel farklılık gibi unsurlara göre şekillenmektedir.

Dunn ve Dunn (1992) öğrenme ortamının fizyolojik etkileri ile öğrenme stillerinin ilişkisi ve çocukların sergiledikleri kinestetik eğilimler ön planda tutulmaktadır. Bunun yanı sıra öğrenme ortamının somut, aydınlık ve tüm duyu organlarına hitap eden unsurlar içermesinin öğrenme stillerini belirlemede etkili olduğu vurgulanmaktadır. Küçük yaş grubu çocukların görsel, algısal, somut ve aktiviteye (kinestetik/dokunsal) dayalı öğrenmeye eğilimli oldukları bilinmektedir (Hawk ve Shah, 2007; Kolb ve Kolb, 2005). Okul öncesi dönemde çocuklar aktif, algısal ve görsel öğrenme stillerini sergilemektedirler (Dunn, Griggs, Olson ve Beasley, 1995). Bunun yanı sıra, son dönemde yapılan bazı araştırmalarda da çocukların bütünsel öğrenmelerinin yanı sıra sıralı (analitik) öğrenme sergiledikleri de tespit edilmiştir (Arnup, Murrihy, Roodenburg ve McLean, 2013). Bu bağlamda okul öncesi dönemde çocukların 
birbirinden farklı öğrenme stillerine sahip olmaları ile birlikte genel anlamda somut, algısal ve görsel öğrenmelere yatkın oldukları söylenebilir.

Çeşitli yaş grupları ile yapılan bazı araştırmalarda cinsiyet değişkeninin öğrenme stilleri üzerinde genel olarak kinestetik, görsel ve algısal alt boyutlarda kızların lehine farka neden olduğu (Gül, 2011; Otrar, 2007; Özkan, 2012; Ewing ve Yong, 1992; Dunn ve Griggs; 1995, Park, Neilsen ve Woodruff, 2013) bazı araştırmalarda ise anlamlı bir farka neden olmadığ ortaya konmuştur (Poyraz, Gülten ve Soytürk, 2012; Çağlayan ve Taşgın, 2009; Şimşek, 2007). Bununla beraber, kızların grup çalışmaların da ve sosyal etkileşimlerde, erkeklerin ise benmerkezci ve yalnız çalışan, rekabetçi karakter sergiledikleri ortaya konmuştur (Garcia, 1994). Alanyazında cinsiyet değişkeninin öğrenme stilleri üzerine etkisinin incelendiği çalışmalarda farklı sonuçların elde edilmesi, bu araştırmada da cinsiyet değişkenin incelenmesinin yarar sağlayacağını göstermektedir.

Felder ve Soloman (1994) öğrenme stilleri indeksinde, aktif-yansıtıcı, algısal sezgisel, görsel-işitsel ve sıralı-bütünsel öğrenme stilleri alanlarına yer vermiştir. Geliştirdikleri öğrenme stilleri indeksinde, katılımcıların iki ayrı kutupta tercih yapmalarını sağlayarak sahip oldukları öğrenme stillerini belirlemeye çalışmışlardır. Felder ve Soloman' in (1994) öğrenme stillerinde yer verdikleri aktif öğrenme, daha çok yaparak, deneyerek ve somut tecrübelerin kullanıldığ öğrenme stili, yansıtıcı öğrenme ise düşünerek ve olaylar arasında bağlantı kurarak gerçekleştirilen öğrenme tercihleri olarak kabul edilmektedir. Algısal öğrenme ise beş duyu organının etkin kullanıldığı ve algılamaya dayalı somut öğrenmeleri içerirken, sezgisel öğrenme de sezgilerin, hislerin, duyguların ve değer yargılarının tercih edildiği daha soyut bir yaklaşım görülmektedir. Görsel öğrenme stillerinde, bireyler için görsel materyaller, tablolar ve grafikler öğrenmeyi kolaylaştırırken, işitsel öğrenme eğilimindeki öğrenenlerde düz metinler ve bu metinlerin sözel olarak ifade edilmesi daha etkilidir. Bütünsel (global) öğrenmeler, olaylara bütüncül bakma ve tümdengelim mantığı ile bakmayı ifade ederken, sıralı (analitik) öğrenmeler, detayları ve tümevarım mantı̆̆ını ifade etmektedir. Diğer öğrenme stili modellerine göre, bilişsel anlamda daha detaylı bilgiler sunan bu model ile okul öncesi çocuklarının öğrenme stillerinin incelenmesinin nedeni, diğer öğrenme stillerinde yer verilen öğrenme mekânlarının fiziksel özelliklerinden bağımsız ve çocukların uzun süreli gözlemini gerektirmeyen pratik bir model olmasından kaynaklanmaktadır. Bu çalışmada Güneş (2014) tarafından geliştirilen ve felsefi temelleri Felder ve Soloman'ın (1994) öğrenme stilleri indeksine dayanan Çocuklar İçin Öğrenme Stili İndeksi (ÇİÖSİ) uygulanmıştır. Çi̇ÖSİ de yer alan öğrenme stili alt boyutlarından aktif öğrenme stili için " $A k$ ", yansitıcı öğrenme stili için " $Y a$ ", algısal öğrenme stili için " $A l$ ", sezgisel öğrenme stili için "Se", görsel öğrenme stili "Gö", işitsel öğrenme stili için "IŞs", bütünsel öğrenme stili için "Bü" ve sıralı öğrenme stili için de "St" sembolleri kullanılmıştır.

\section{Araştırmanın önemi ve amacı}

$\mathrm{Bu}$ araştırmanın başlıca önemi, okul öncesi çocuklarının öğrenme stillerinin incelenerek, eğitim programlarının daha etkili uygulanmasına ve değerlendirme süreçlerinin de çocukların ilgi ve yeteneklerine göre şekillenmesine katkı sağlamaktır. Bunun yanı sıra, uygulama temelli Çi̇ÖSİ' nin öğrenme stilleri konusunda alanyazında kullanılabilecek alternatif bir ölçüm aracı olarak değerlendirilmesi, araştırmanın diğer önemi olarak düşünülmektedir. Ailelerin, çocuklarını öğrenme eğilimleri, öğrenme tercihleri/stilleri, ilgileri ve yetenekleri çerçevesinde tanımaları araştırmanın başka bir önemi olarak görülmektedir. Bu bağlamda araştırmanın amacı, çocukların öğrenme stillerinin belirlenmesi ve cinsiyet değişkeninin öğrenme stillerinde anlamlı bir farka neden olup olmadığının incelenmesidir.

\section{Yöntem}

Araştırma, nicel araştırma yöntemlerinden betimsel nitelikli tarama modelidir (Büyüköztürk, Çakmak, Akgün, Karadeniz ve Demirel, 2010). 


\section{Örneklem/Çalışma Grubu}

Araştırma grubu, amaçsal örnekleme yöntemi olan ölçüt örneklemine uygun ve seçkisiz (rastgele) olarak seçilmiştir (Büyüköztürk, Çakmak, Akgün, Karadeniz ve Demirel, 2010). Çalışma, 2014-2015 akademik yılında Ankara ilinde MEB' e bağlı 3 devlet anaokuluna devam eden 60-72 ay grubundan $64 \mathrm{klz}$ ve 64 erkek olmak üzere toplam 128 çocukla yürütülmüştür. Araştırmanın konusu olmamasına rağmen tek yönlü sonuçlardan kaçınma amacı ile örneklem alt, orta ve üst Sosyo-ekonomik düzey (SED)'i dengeli sayılabilecek şekilde temsil eden gruplardan seçilmiş̧ir. Çalışmanın örneklem grubuna ilişkin SED bilgileri Tablo 1' de sunulmuştur.

Tablo 1. Çalışma Grubunun SED' e Göre Oransal Dă̆ılımı

\begin{tabular}{lc}
\multicolumn{1}{c}{ Çalışma grubu } & Oran (\%) \\
\hline Alt SED & 38 \\
Orta SED & 30 \\
Üst SED & 32 \\
\hline
\end{tabular}

\section{Veri toplama araçlart}

Araştırmada çocukların öğrenme stillerinin belirlenmesi amacıyla Güneş (2014) tarafından geliştirilen, felsefi temelleri Felder ve Soloman' in (1994) Index of Learning Style' e (ILS) dayanan, uygulama temelli, yansıtıcı/aktif (Ya/Ak), sezgisel/algısal (Se/Al), işitsel/görsel (İș/Gö) ve sıralı/bütünsel (S1/Bü) olmak üzere 4 alt boyuttan ve her alt boyut için 7 madde olmak üzere toplam 28 sorudan oluşan 2' li tercihler içeren Çocuklar İçin Öğrenme Stili İndeksi (Çi̇ÖSİ- Index of Learning Styles for Children) uygulanmıştır. ÇİÖSİ örnek maddeleri Tablo 2' de sunulmuştur.

Tablo 2. ÇIÖSI Örnek Maddeleri

\begin{tabular}{|c|c|c|c|}
\hline $\begin{array}{l}\text { ÇİÖSİ Alt } \\
\text { boyutlar }\end{array}$ & Madde & & Yanitlar \\
\hline Aktif/ & 21- Bu kilidi hangi anahtar & Deneyerek bulur & Düşünerek (akıl yürüterek) \\
\hline Yansitic1 & açar & (Aktif tercih) & bulur (Yansitici tercih) \\
\hline Algisal/ & 14- Hangi kitabı okuyalım & Gezegenimiz Dünya & Kurallara uymazsam ne \\
\hline Sezgisel & & (Alg1sal tercih) & olur? (Yansitic1 tercih) \\
\hline Görsel/ İşitsel & 15- Daha çok detay verir & $\begin{array}{l}\text { Resim gösterilip soru } \\
\text { sorulur (Görsel } \\
\text { tercih) }\end{array}$ & $\begin{array}{l}\text { Resimsiz metin okunur ve } \\
\text { soru sorulur (İşitsel tercih) }\end{array}$ \\
\hline $\begin{array}{l}\text { Bütünsel/ } \\
\text { Siralı }\end{array}$ & $\begin{array}{l}\text { 8- Resimde gösterilen } \\
\text { arabayı yapmak istiyoruz } \\
\text { ama bazı parçalar fazla } \\
\text { konulmuş, sence bunlar } \\
\text { hangileri? }\end{array}$ & $\begin{array}{l}\text { Resme bakarak fazla } \\
\text { olan parçayı bulur } \\
\text { (Bütünsel tercih) }\end{array}$ & $\begin{array}{l}\text { Arabayı yeniden yaparak } \\
\text { fazla parçaları ayırır (Sıralı } \\
\text { tercih) }\end{array}$ \\
\hline
\end{tabular}

\section{ÇïöSİ güvenirlik-geçerlilik bilgileri}

ÇİÖSİ' nin bu araştırmadan bağımsız geliştirilme çalışmalarında aşağıda sunulan güvenirlikgeçerlik sonuçlarına ulaşılmıştır. ÇİÖSİ' nin güvenirlik çalışmaları kapsamında, madde analizleri için madde-toplam puan korelasyonu (Pearson korelasyon analizi), bağımsız uygulayıcılar arasındaki uyum (bağımsız gruplar t-Testi) ve iç-tutarlılık içinde Cronbach alpha değerleri hesaplanmıştır. ÇiÖSİ geçerlilik çalışmalarında Davis tekniği kullanılarak kapsam geçerliliği, yapı geçerliliği içinde açımlayıcı faktör analizi (explorer factor analyses) yapılmıştır. ÇIÖSİ'nin normallik testleri için çarpıklık-basıklık, Shapiro-Wilk testleri ile histogram grafikleri incelenmiştir. $\mathrm{Bu}$ araştırma ölçek geliştirme çalışması olmadığı için ÇïÖSİ' nin güvenirlik geçerlik sonuçları kısaca aşağıdaki bölümlerde sunulmuştur. 


\section{ÇİöSí güvenirlik bilgileri}

Güvenirlik çalışmalarından madde-toplam puan korelasyon işlemine göre madde değerlerinin istatistiksel olarak anlamlı $(\mathrm{p}=.000)$ ve "iyi madde" $(.30 \leq \mathrm{r} \leq .39)$ ile "çok iyi madde" olarak kabul edilen $(\mathrm{r} \geq .40)$ sınırlarda olduğu tespit edilmiştir (Büyüköztürk, 2007). ÇïÖSİ araştırma süresince iki bağımsız uygulayıcı tarafından uygulanmış ve uygulayıcılar arasındaki uyum düzeyinin yapılan Pearson korelasyon analizi sonucuna göre yaklaşı olarak \%73 olduğu bulunmuştur $(\mathrm{r}=.726)$. ÇïÖSİ' nin iç tutarlılık çalışmalarında 0-1 kodlama mantığ 1 içiren ölçeklerde hesaplanan KR-20 ya da KR-21 testleri yerine ILS' nin önceden yapılan güvenirlikgeçerlilik çalışmalarında kullanılan ve her bir alt boyut için ayrı hesaplanan Cronbach alpha değerleri bulunmuştur (Felkel ve Gosky, 2012; Litzinger, Lee, Wise ve Felder, 2005; Livesay, Dee, Nauman ve Hites 2002; Zywno, 2003). Cronbach alpha değerleri, Ya/Ak alt boyutu için $.711, \mathrm{Se} / \mathrm{Al}$ alt boyutu için .677, İş/Gö alt boyutu için .741 ve S1/Bü alt boyutu için de .724 olarak hesaplanmıştır. Alt boyutlar için hesaplanan iç-tutarlılık katsayısının önceki çalışmalarda (Felkel ve Gosky, 2012; Litzinger, Lee, Wise ve Felder, 2005; Livesay, Dee, Nauman ve Hites 2002; Zywno, 2003) bulunan değerlere yakın ve bazılarından yüksek olması, indeksin kullanılabilecek ölçüde güvenilir olduğunu göstermektedir.

\section{ÇíÖSI geçerlilik bilgileri}

ÇiÖSİ'nin geliştirilme aşamalarında kapsam geçerlilik çalışmaları için Davis Tekniğinden (1992) yararlanılmış ve 10 uzman görüşü [2 ölçme değerlendirme uzmanı (25-30 yıllık deneyimli), 3 çocuk gelişim uzmanı (20-25 yıllık deneyimli), 2 okul öncesi eğitim uzmanı (2025 y1llık deneyimli), okul öncesi öğretmeni (15 y1llık deneyimli), çocuk psikologu (10 y1llık deneyimli) ve çeviriler için yabancı dil uzmanı (5 yıllık deneyimli)] üzerinden ÇïÖSİ maddelerinin Kapsam Geçerlilik İndeks (KGİ) değerlerinin 0.8 ile 1.00 arası değişen değerlerde olduğu hesaplanmıştır. Ana uygulamalar öncesinde 60-72 ay grubundan 55 çocukla 3 pilot uygulama gerçekleştirilmiş ve ÇïÖSİ'nin nihai formuna ulaşılmıştır.

ÇïÖSİ faktör analizi öncesi yapılan KMO ve Barlett Test sonuçlarına göre indeksin faktör analizine uygun olduğu görülmüştür (KMO .594, Barlett $\mathrm{p}=.000)$. KMO değerinin .500 ' den büyük olması faktör analizi için yeterli kabul edilmektedir (Field, 2000). Faktör analizi sonuçlarında ise, maddelerin faktörlere bağlanma değerlerinin (extraction) .460 ile .880 arasında değiştiği görülmüş ve bağlanma değerlerinin $\geq .450$ olması, maddelerin indekse güçlü şekilde bağlandığının ve indeksinde sağlam denebilecek bir yapıda olduğunun göstergesi olarak kabul edilebilir (Büyüköztürk, 2007). Çı̈ÖSİ' nin faktör analizi sonuçlarında maddelerin 4 alt boyutta dağılım gösterdiği bulunmuştur. Bu sonuçlar 1şığında ÇïÖSİ' nin araştırmada kullanılabilecek güvenirlik ve geçerlikte olduğu söylenebilir.

\section{Normallik testleri}

ÇİÖSİ'nin parametrik ya da non-parametrik test özelliğinin sınanması amacıyla normallik testleri uygulanmıştır. Normallik testleri kapsamında, çarpıklık ve basıklık katsayıları, ShapiroWilk testleri ve histogram grafikleri incelenmiştir. Çarpıklık ( $z=.397)$ ve basıklık $(z=-.999)$ katsayılarının normal dağılım aralığında olduğu bulunmuştur $(-1.96 \leq z \leq+1.96)$. Shapiro-Wilk testlerinin normallik ölçümlerinde daha hassas sonuçlar verdiği için tercih edilmiş (Elliot ve Woodward, 2007) ve p değeri=.100 >.005 olarak hesaplanarak normal dağılım gösterdiği sonucuna ulaşılmıştır. Son olarak çizilen histogram grafiklerinde ÇïÖSİ' nin tüm alt boyutlarda normal dağglım gösterdiği görülmüştür. Yapılan normallik testleri sonucunda Çi̇ÖSİ'nin normal dağılım gösteren parametrik test özelliğine sahip bir uygulama aracı olduğu sonucuna ulaşıllmıştır.

\section{ÇïÖSİ' nin uygulama süreci}

ÇİÖSİ 2013-2014 ile 2014-2015 güz ve bahar dönemlerinde uygulanmıştır. Çiösİ uygulamaya ve tercihlere dayalı bir mantıkla hazırlanmıştır. Çocukların uygulama yapabilmesi ve tercihlerde bulunabilmesi için her madde için materyaller kullanılmıştır/hazırlanmıştır. Bu materyaller indeks maddelerinin içeriğine uygun olarak, kitaplar, parçadan-bütüne, bütünden-parçaya 
mantığı ile hazırlanan matematik problemleri ve detayların gizlendiği resimleri içermektedir. ÇïÖSİ çocuklara bireysel olarak uygulanmakta ve uygulayıcı tarafından çocukların yanıtları ile ilişkili olan öğrenme stili indeks üzerinde kodlanmaktadır. Ortalama ÇïÖsİ uygulama süresi 2025 dakika olarak ölçülmüştür.

\section{Uygulamanın etik işlemleri}

Araştırmanın etik boyutu ile ilgili olarak, çalışmada yer alan çocuklar için MEB' den etik kurul izni alınmış, okul yönetimleri ve öğretmenler bilgilendirilmiş, isteyen okullara araştırma sonuçları "sadece kendi okullarını kapsayan şekliyle ve araştırmada yer alan çocuklarının isimleri gizli kalacak şekilde" sunulmuştur. Bunun yanı sıra veliler için bilgilendirme formları hazırlanarak, çocuk gönüllü katılım formları ile ailelerinden izin alınmış ve isteyen velilerle çocuklarının sonuçları paylaşılmıştır.

\section{Veri analizi}

Çİ̈Sİ zıt kutuplu öğrenmeleri içeren bir ölçüm aracı olduğu için, ölçek üzerinde yapılan her $\mathrm{Ak} / \mathrm{Al} / \mathrm{Gö/Bü} \mathrm{tercihleri} \mathrm{için} \mathrm{"+"} \mathrm{ve} \mathrm{zıt} \mathrm{kutupta} \mathrm{yer} \mathrm{alan} \mathrm{her} \mathrm{Ya} / \mathrm{Se} / \mathrm{Işs} / \mathrm{S} 1$ öğrenme stili alt boyutu tercihleri içinde "-" sembolik değerleri kullanılmıştır. İndeksteki öğrenme stili alt boyut puanları kullanılan sembollerin frekansları dikkate alınarak hesaplanmıştır. Öğrenme stili frekans değerlerinden elde edilen puanlar, öğrenme stillerinin betimlenmesinde ve öğrenme stillerinin cinsiyet değişkenine göre farklılaşıp farklılaşmadığının incelendiği bağımsız gruplar t-Testi işleminde kullanılmıştır.

\section{Bulgular}

\section{Çocukların öğrenme stillerine ilişkin bulgular}

ÇIÖSİ sonuçlarının frekans değerleri ve öğrenme stilleri sonuçları Tablo 3' de sunulmuştur.

Tablo 3. Çİ̈Sİ Sonuçlarının Frekans Değerleri ve Öğrenme Stilleri Sonuçları

\begin{tabular}{lllll}
\hline Eksenler & Ya & Ak & Se & Al \\
\hline Frekanslar (f) & 316 & 580 & 504 & 392 \\
Öğrenme stili & $\% 35.27$ & $\% 64.73$ & $\% 56.25$ & $\% 43.75$ \\
eğilim oranları & $(316 / 896)$ & $(580 / 896)$ & $(504 / 896)$ & $(392 / 896)$ \\
Eksenler & İş & Gö & S1 & Bü \\
Frekanslar (f) & 296 & 600 & 474 & 422 \\
Öğrenme stili & $\% 33.04$ & $\% 66.96$ & $\% 52.90$ & $\% 47.10$ \\
eğilim oranları & $(296 / 896)$ & $(600 / 896)$ & $(474 / 896)$ & $(422 / 896)$ \\
\hline
\end{tabular}

Araştırmaya katılan 128 çocuğun toplu sonuçlarının sunulduğu Tablo 3 incelendiğinde, çocukların aktif/sezgisel/görsel ve sıralı öğrenmeye yatkın oldukları görülmektedir. Çocukların ÇïÖSİ' de yer alan öğrenme stillerinden \%65 oranda aktif, \%56 oranda sezgisel, \%67 oranda görsel ve $\% 53$ oranda sıralı öğrenme stili eğiliminde oldukları görülmektedir. Çocuklar genel olarak, aktif öğrenmeyi yansıtıcı öğrenmeye göre \%30 [(\%65-\%35)], sezgisel öğrenmeyi algısal öğrenmeye göre \%12 [(\%56-\%44)], görsel öğrenmeyi işitsel öğrenmeye göre \%34 [(\%67$\% 33)]$, sıralı öğrenmeyi de bütünsel öğrenmeye göre \%5 [(\%53-\%47)] oranla daha fazla tercih etmektedir. Elde edilen oranlar dikkate alındığında en baskın öğrenme stilinin \%67 oranla görsel ve \%65 oranla aktif öğrenme olduğu anlaşılmaktadır. Öte yandan çocukların sıralı (\%53) ve bütünsel (\%47) öğrenme stillerini daha dengeli kullandıkları fark edilmektedir.

\section{Cinsiyet değiş̧enine göre çocukların öğrenme stillerine iliş̧kin bulgular}

Cinsiyet değişkenine göre çocukların öğrenme stillerine ilişkin bulgular Tablo 4' de sunulmuştur. 
Tablo 4. Çocukların Cinsiyetlerine Göre Öğrenme Stili Tercihlerinin Betimsel İstatistik Sonuçları

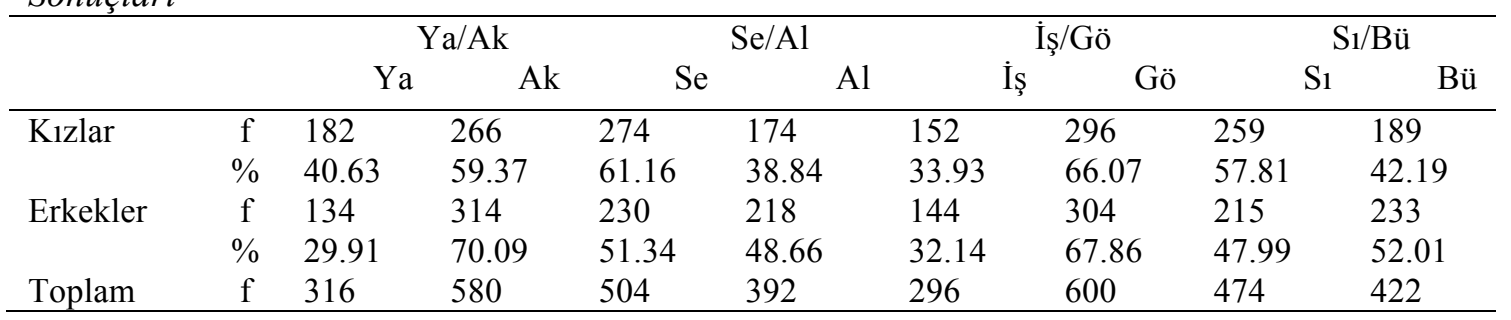

Tablo 4'de kız ve erkek çocukların öğrenme stilleri oranları incelendiğinde, aktif/sezgisel/görsel/sıralı öğrenme stili oranlarının diğer öğrenme stili oranlarına göre daha yüksek oranlara sahip olduğu görülmektedir. Kızlarda öğrenme stili tercihlerinin aktif (\%60), sezgisel (\%61) ve görsel (\%66) öğrenme boyutlarında radikal şekilde yüksek bir eğilim gösterdiği, erkeklerde de aktif $(\% 70)$ ve görsel (\%68) öğrenme boyutlarında radikal şekilde yüksek bir eğilim gösterdiği görülmektedir. Erkek çocuklar kız çocuklardan farklı olarak Se/Al boyutunda her iki öğrenme stilini de birbirine yakın oranlarda kullanmaktadırlar $(\mathrm{Se}=\% 51$, $\mathrm{Al}=\% 49)$.

Çocuklarının cinsiyetlerine göre öğrenme stillerine ilişkin bağımsız gruplar t-Testi sonuçları Tablo 5' de sunulmuştur.

Tablo 5. Çocuklarının Cinsiyetlerine Göre Öğrenme Stillerine İlişskin Bă̆ımsız Gruplar T-Testi Sonuçları

\begin{tabular}{llrllll}
\hline Alt boyutlar & Grup & $\overline{\mathbf{x}}$ & $\mathrm{SS}$ & $\mathrm{df}$ & $\mathrm{t}$ & $\mathrm{p}$ \\
\hline $\mathrm{Ya} / \mathrm{Ak}$ & Kizlar & 9.84 & 2.03 & 126 & -2.165 & .032 \\
& Erkekler & 9.09 & 1.88 & & -2.165 & \\
$\mathrm{Se} / \mathrm{Al}$ & Kizlar & 11.28 & 1.93 & 126 & -1.975 & .047 \\
& Erkekler & 10.59 & 1.99 & & -1.975 & \\
İş/Gö & Kizlar & 9.37 & 2.07 & 126 & -.348 & .729 \\
& Erkekler & 9.25 & 1.99 & & -.348 & \\
$\mathrm{~S}$ 1/Bü & Kizlar & 11.04 & 2.23 & 126 & -1.852 & .066 \\
& Erkekler & 10.35 & 1.95 & & -1.852 & \\
\hline
\end{tabular}

$\mathrm{N}_{\mathrm{kzz}}=\mathrm{N}_{\text {erkek }}=64$

Bağımsız Gruplar t-Testi sonucuna göre cinsiyet değişkeni, yansıtıcı ve sezgisel öğrenme alt boyutların da kızlar lehine istatistiksel olarak anlamlı farka neden olmaktadır. Kızların yansıtıcı öğrenme toplam puanlarının 9.84, sezgisel öğrenme toplam puanlarının 11.28 olarak bulunurken, erkek çocuklarında bu stillerin toplam puanları sırasıyla 9.09 ve 10.59 olarak bulunmuştur. $\mathrm{Bu}$ sonuçlara göre, kız çocukları erkek çocuklarından, yansıtıcı ve sezgisel öğrenme boyutlarından istatistiksel olarak anlamlı şekilde farklılaşmaktadır.

\section{Tartışma}

ÇIÖSİ sonuçlarına göre çocukların genel olarak aktif/sezgisel/görsel ve sıralı (analitik) öğreniciler olduğu bulunmuştur. ÇİÖSì üzerinde yapılan betimsel istatistik sonuçlarına göre aktif öğrenme \%65 ve görsel öğrenme \%67 ile en baskın öğrenme stilleri olarak belirlenmiştir. Bunun yanı sıra sezgisel-algısal ve sıralı-bütünsel öğrenmelerin daha dengeli oranda kullanıldıkları hesaplanmıştır. Çocukların öğrenme stillerinin aktif ve görsel öğrenme alt boyutlarında yoğunlaştığ 1 , bununla beraber algısal/sezgisel ve bütünsel/sıralı alt boyutlarında yer alan her iki öğrenme stilinin de birbirine çok yakın olduğu söylenebilir. Küçük yaş grubu çocuklarının görsel, algısal, somut ve aktiviteye (kinestetik/dokunsal) dayalı öğrenmeye eğilimli oldukları bilinmektedir (Kolb ve Kolb, 2005). Çocuklarının aktif, algısal ve görsel öğrenme stillerini sergilemeleri, genel anlamda literatürle bağdaştığı söylenebilir (Dunn ve diğerleri, 1995; Hawk ve Shah, 2007; Jarvis, George, ve Holland, 2012; Kolb ve Kolb, 2005; Lebel ve 
Beaulieu, 2011). Öte yandan araştırma bulgularına göre okul öncesi dönem çocuklarının sıralı öğrenme (analitik) tercihlerini de gösterdikleri tespit edilmiştir. Elde edilen bu bulgu çocuklar bütünsel öğrenir görüşü (Dunn, Griggs, Olson ve Beasley, 1995) ile çelişse de son dönemde yapılan ve çocukların analitik düşünebildiklerine yönelik bulgularla (Arnup, Murrihy, Roodenburg ve McLean, 2013; Koyré, 2000) paralellik gösterdiği görülmektedir. Arnup, Murrihy, Roodenburg ve McLean (2013) çocukların analitik/imgesel, analitik/sözel, bütünsel/imgesel ve bütünsel/sözel bilişsel stillerine sahip oldukları rapor edilmiştir. Koyré (2000) ise zihnin bazı durumlarda bütüne ulaşmada parçalara ayırma ve bu parçaları sıralı düzende öğrenme eğiliminde olduğunu bildirmektedir. Çocukların bütünsel/sıralı alt boyutunda daha analitik ve sıralı öğrenme eğilimleri sergilemeleri Koyré'in (2000) önermesi ile uyumlu bir sonuç olarak değerlendirilebilir. Healy (2004) ise düşünce özelliklerini kategorilerken sıralı düşünme ile analitik düşünmeyi aynı özellik altında değerlendirmiştir ve çocukların üst yaş gruplarına geçtikçe sıralı düşünmenin etkisinde gelişen analitik bir düşünce sistemine yöneldikleri belirtmiştir, bu açıdan araştırmada elde edilen analitik düşünceye ilişkin bulgular ilerde gelişecek analitik düşünceye ait ilk adımlar olarak yorumlanabilir. Burada dikkat edilecek diğer bir bulgu ise, çocukların sezgisel öğrenme stiline sahip olmasıdır. Her ne kadar okul öncesi dönemde çocukların somut ve yaşantılara dayalı öğrenmeleri gerçekleştirdikleri bilinse de çocukların ÇíÖSİ de algılayamadıkları ama sezebildikleri bilgileri öğrenme ve daha soyut öğrenmelere karşı gösterdikleri motivasyonlarının olduğu görülmüştür. Bu bağlamda çocukların soyut ve sezgisel öğrenmeye karşı eğilimlerinin olduğu düşünülmektedir. Öte yandan bu düşünceye ilişkin tez ve anti-tezlerde mevcuttur, Kolb (1984) öğrenme aşamalarında soyut kavramsallaştırmayı somut yaşantılardan sonra değerlendirirken, Gregorc (1979) ise bireylerin somut ya da soyut öğrenme stillerine herhangi bir aşamayı takip etmeksizin de sahip olabileceklerini belirtmektedir.

Cinsiyet değişkenine göre öğrenme stilleri incelendiğinde kızların yansıtıcı ve sezgisel öğrenmeyi erkeklerden daha yoğun şekilde tercih ettikleri sonucuna ulaşılmıştır. Kız çocuklarının aktif/sezgisel/görsel ve sıralı, erkek çocuklarının ise aktif/sezgisel/görsel ve bütünsel öğrenme stillerine sahip oldukları sonucuna ulaşılmıştır. Grupların karşılaştırılmasının yapıldığı t-Testi sonuçlarında da kızların yansıtıcı ve sıralı (analitik) öğrenmede erkeklere göre anlamlı şekilde farklılık gösterdiği sonucuna ulaşılmıştır. Cinsiyet değişkeni ile ilgili daha önce yapılan araştırmalarda kızların sosyal etkileşim stillerinin öğrenme biçimlerini etkilediği, buna bağlı olarak kızların göz teması kurma, grupla öğrenme, işitsel/sözlü öğrenme eğilimlerinin erkek çocuklara oranla daha baskın olduğu, erkek çocuklarda ise daha ben-merkezci, rekabete dayalı, hırçın ve bireysel becerilerini gösterebildikleri konu/eylemleri tercih ettiklerinden, öğrenmelerinde daha bireysel öğrenme eğilimi sergiledikleri bildirilmiştir (Garcia, 1994). Diğer araştırma sonuçlarında ise kız çocuklarının erkeklere göre daha kinestetik, görsel ve algısal öğrendikleri rapor edilmiştir (Dunn vd.,1995; Park, Neilsen ve Woodruff, 2013). Bu bilgiler 1şı̆̆ında, erkek çocuklarda tespit edilen ve bireyselliğin ön planda olduğu aktif, fiziksel aktiviteler ve etkinliğe dayalı algısal öğrenme stili ile kızlarda gözlenen ve düşüncenin ağırlıklı olduğu sezgisel öğrenme stili bulgularının ilgili alanyazınla paralellik gösterdiği söylenebilir.

\section{Sonuçlar ve Öneriler}

Yapılan araştırmada genel olarak çocukların aktif/sezgisel/görsel ve sıralı (analitik) öğreniciler olduğu bulunmuştur. Çocukların öğrenme stillerinden aktif ve görsel alt boyutlarında yoğunlaştığı, bununla beraber algısal/sezgisel ve bütünsel/sıralı alt boyutlarında yer alan her iki öğrenme stilinin de birbirine çok yakın olduğu söylenebilir. Araştırmanın alt problemlerinden cinsiyet değişkenine göre öğrenme stilleri incelendiğinde erkeklerin aktif ve algisal öğrenmeyi istatistiksel olarak anlamlı şekilde kızlardan daha yoğun şekilde tercih ettikleri sonucuna ulaşılmıştır. Erkek çocuklarının aktif/sezgisel/görsel ve bütünsel, kız çocuklarının ise aktif/sezgisel/görsel ve sıralı öğrenme stillerine sahip oldukları sonucuna ulaşılmıştır. Grupların karşılaştırılmasının yapıldığı t-Testi sonuçlarında iki grup arasında kızların lehine yansıtıcı ve sıralı (analitik) öğrenmede erkeklere göre anlamlı şekilde farklılık gösterdiği sonucuna ulaşılmıştır. 
Araştırmanın sınırlılıkları olarak örneklem sayısı, uygulama okullarının yapısı ve uygulayıcı sayısı gösterilebilir. Çalışma 128 çocukla yürütülmüştür ve bu araştırmadaki örneklem sayısı, öğrenme stilleri gibi bireysel farklılıkların etkili olduğu çalışma konuları için tartışma konusu olabilir. Araştırmanın yapıldığ 1 devlet okullarındaki standart program uygulaması sonuçlar üzerinde öngörülemeyen ve manipüle edilemeyen tek yönlü sonuçlar doğurmuş olabilir. Uygulamalar iki bağımsız uygulayıcı tarafından yürütülmüştür, uygulama aracının nitel veri toplamaya yönelik yapısından dolayı iki ile sınırlı kalan uygulayıcı ve kodlayıcı sayısının araştırma için bir sınırlılık oluşturduğu kabul edilebilir. Araştırmanın sinırlılıkları kapsamında getirilecek öneriler, okul öncesi dönem gruplarından daha fazla sayıda katılımcı ile boylamsal çalışmalar şeklinde sürdürülebilir, öğrenme stillerinin oluşumu ve gelişiminde etkisi olabilecek değişkenler belirlenebilir.

Uygulamaya yönelik öneriler kapsamında, Çi̇ÖSİ okul öncesi dönemde çocuğun tanıma ve değerlendirilmesinde kullanılabilir. Okul öncesi eğitim programları öğrenme stillerine göre tekrar gözden geçirilebilir. Öğretmenler öğrenmenin etkililiği ve maksimum öğrenme kapasitesine ulaşma yolunda çocukların çok ve az tercih ettikleri öğrenme stillerinin geliştirilmesine fırsat tanıyacak öğrenme ortamları ve etkinleri planlanabilir. Öğretmenlerin ve geliştirilen programların değerlendirme yöntemleri çocukların öğrenme stillerine göre düzenleyebilirler. Son olarak ailelere yönelik öneriler kapsamında da, aileler, ÇİÖSİ'de yer alan etkinlikleri uygulayarak daha küçük yaşlardan itibaren çocuklarının öğrenme stilleri eğilimleri hakkında bilgi sahibi olabilirler. Çocuklarının öğrenme etkinliklerine imkân sağlayacak araçgereç ve ya ortamları, onların öğrenme stillerine uygun olarak seçebilirler.

\section{Kaynaklar}

Arnup, J.L., Murrihy, C., Roodenburg, J., \& McLean, L.A. (2013). Cognitive style and gender differences in children's mathematics achievement. Educational Studies, 39(3), 355368. doi: 10.1080/03055698.2013.767184

Balat, G., Bilgin, H. ve Özdemir, A.A. (2012). 5-6 yaş çocukları için öğrenme stilleri ölçek geliştirme çalışması. Illköğretim Online, 11(2), 480-490.

Büyüköztürk, Ş. (2007). Veri analizi el kitabı (8. Bask1). Ankara: PegemA Yayınc1lık.

Çağlayan, H.S. ve Taşğın, Ö. (2009). Beden eğitimi ve spor yüksekokulu sınavına başvuran aday öğrencilerin öğrenme biçimlerinin incelenmesi. Selçuk Üniversitesi Sosyal Bilimler Enstitüsü Dergisi, 20,199-212.

Dunn, R. (1986). Learning styles: Link between individual differences and effective instruction. North Carolina Educational Leadership, 2(1), 4 - 22.

Dunn, R., \& Dunn, K. (1992). Teaching secondary students through their individual learning styles. Practical Approaches For Grades 3-6. Massachusetts: Allyand Bacon, USA.

Dunn,R., Griggs, S.A., Olson, J., \& Beasley, M. (1995). A meta-analytic validation of the Dunn and Dunn model learning-style performances. The Journal of Educational Research, 88(6), 353-363.

Elliott, A.C., \& Woodward, W.A. (2007). Statistical analysis quick reference guidebook with SPSS examples. London: Sage Publications.

Ewing, N.J., \& Yong, L.F. (1992). A comparative study of the learning style preferences among gifted African-American, Mexican-American and American-Born, Chinese middlegrade students. Roeper Review, 14(3),120-123.

Felder, R.M., \& Brent, R. (2005). Understanding students differences. Journal of Engineering Education, 57-72.

Felder, R.M., \& Silverman, L. (1988). Learning and teaching styles in engineering education. Engineering Education, 78(7), 674-681.

Felder, R.M., \& Soloman, B.A. (1994). Index of learning styles. http://www.ncsu.edu/felderpublic/ILSpage.html.

Felkel, B., \& Gosky, R.M. (2012). A study of reliability and validity of the Felder-Soloman index of learning styles for business students. Electronic Proceedings of the Twenty- 
fourth Annual International Conference on Technology in Collegiate Mathematics Orlando, Florida, 22-25 March 2012 (pp. C004).

Field, A. (2000). Discovering statistic using SPSS for Windows. London - Thousand Oaks New Delhi: Sage Publications.

Fleming, N.D. (2001). Teaching and learning styles: VARK strategies. New Zealand: Christchurch.

Garcia, C. (1994). Gender differences in young children's interactions when learning fundamental motor skills. Research Quarterly for Exercise and Sport, 65(3), 213-225.

Grasha, A.F. (1996). Teaching with style. Pittsburgh, PA: Alliance.

Gregorc, A.F. (1979). Learning/teachingstyles: Their nature and effects. NASSP Monograph, (October/November), 19-26.

Gül, B. (2011). Ortaöğretim öğrencilerinin öğrenme stilleri ile ders çalışma stratejileri arasındaki iliş̧kinin incelenmesi (Beşiktaş İlçesi Örneği). Yayınlanmamış yüksek lisans tezi. İstanbul: Yeditepe Üniversitesi Sosyal Bilimler Enstitüsü.

Güneş, G. (2014). Çocukların epistemolojik görüşlerinin ve ögrenme stillerinin Öklidyen geometrisinde modellenmesi. Yayınlanmamış doktora tezi. Ankara: Hacettepe Üniversitesi.

Hawk, T.F., \& Shah, A.J. (2007). Using learning styles instruments to enhance student learning. Decision Sciences Journal of Innovative Education, 5(1), 1-19, http://onlinelibrary.wiley.com/doi/10.1111/j.1540-4609.2007.00125.x/pdf adresinden 03.02.2013 tarihinde alınmıştır

Healy, J.M. (2004). Your child's growing mind: Brain development and learning from birth to adolescence. New York: Broadway Books.

Jarvis, P., George, J., \& Holland, W. (2012) The Early Years Professional's Complete Companion (second edition). Harlow: Pearson Longman.

Jonassen, D.H., \& Grabowski, B.L. (1993). Handbook of individual differences, learning and instruction. Hillsdale, NJ: Lawrence Erlbaum Associates.

Keefe, J.W. (1979). Learning Style: An Overview. In J.W. Keefe (Ed.), Student learning styles: diagnosing and prescribing programs, Reston, Va: National Association of Secondary School Principals.

Kolb, D.A. (1984). Experiential learning: Experience as the source of learning and development. Englewood Cliffs, NJ: Prentice Hall.

Kolb, D.A. (1976). Learning style inventory. Boston, MA: Hay Group, Hay Resources Direct.

Kolb, A.Y., \& Kolb, D.A. (2005). Learning styles and learning spaces: Enhancing experiential learning in higher education. Academy of Management Learning \& Education, 4(2), $193-212$.

Koyré, A. (2000). Bilim tarihi yazıları I. Ankara: Tübitak Popüler Bilim Kitapları.

Lebel, C., \& Beaulieu, C. (2011). Longitudinal development of human brain wiring continues from childhood into adulthood. The Journal of Neuroscience,31(30), 10937-10947.

Leite, W.L., Svinicki, M., \& Shi, Y. (2010). Attempted validation of the scores of the VARK: Learning styles inventory with multi trait-multi method confirmatory factor analysis models. Educational and Psychological Measurement, 70(2), 323-339.

Litzinger, T.A., Lee, S.H., Wise, J.C., \& Felder, R.M. (2005). A study of the reliability and validity of the felder-soloman index of learning styles. In American Society for Engineering Education Annual Conference \& Exposition. http://www4.ncsu.edu/unity/lockers/users/f/felder/public/ILSdir/Litzinger_Validation_S tudy.pdf adresinden 04.09.2014 tarihinde alınmıştır.

Livesay, G.A., Dee, K.C., Nauman, E.A., \& Hites , L.S. (2002). Engineering student learning styles: A statistical analysis using Felder's index of learning styles. In Annual Conference of the American Society for Engineering Education, Montreal, Quebec.

Miyake, A., \& Friedman, N.P. (2012). The nature and organization of individual differences in executive functions: Four general conclusions. Current Directions in Psychological Science, 21(1), 8-14. 
Otrar, M. (2007). Marmara öğrenme stilleri ölçeğinin geçerlilik ve güvenirlilik çalışması. Kuram ve Uygulamada Eğitim Bilimleri, 7(3), 1379-1419.

Özkan, Ş. (2008). Modeling elementary students' science achievement: the interrelationships among epistemological beliefs, learning approaches, and self-regulated learning strategies. The Doctoral Thesis, Middle East Technical University, Ankara.

Park, H., Neilsen, W., \&Woodruff, E. (2013). Students' conceptions of the nature of science: perspectives from Canadian and Korean middle school students. Sci \& Educ, doi 10.1007/s11191-013-9613-6.

Poyraz, C., Gülten, D.Ç. ve Soytürk, İ. (2012). Öğrenme stillerinin ilköğretim 7. sinıf öğrencilerinin matematik başarısı üzerine etkisi. Hasan Ali Yücel Eğitim Fakültesi Dergisi, 9(1), 1-11.

Passer, M.W., \& Smith, R.E. (2008). The science of mind and behavior (4th ed.). McGraw-Hill.

Şimşek, Ö. (2007). Marmara ögrenme stilleri ölçeğinin geliştirilmesi ve 9-11 yaş çocuklarının ögrenme stillerinin incelenmesi. Yayınlanmamış doktora tezi. İstanbul: Marmara Üniversitesi Eğitim Bilimleri Enstitüsü.

Wilson, J.A.R., Robeck, M.C., \& Michael, W.B. (1974). Psychological foundations of learning and teaching (2nd ed). McGraw Hill, New York.

Zywno, M.S. (2003). A contribution of validation of score meaning for Felder-Soloman's index of learning styles. In Annual Conference of the American Society Engineering Education, Washington, DC.

\section{Extended Abstract}

\section{Introduction}

The regulation ability of thoughts and behaviors of people ability is different from each other, and individual differences are effective in the determination of personal choices. Individual differences play important role in intelligence, cognitive styles, and behaviors, but also in the teaching and learning process (Jonassen \& Grabowski, 1993). It is known that individuals have unique learning strategies and learning styles because of the effects of individual differences on learning (Dunn, 1986; Dunn \& Dunn, 1992, Felder \& Silverman, 1988; Gregorc, 1979; Kolb, 1976). According to Dunn, Griggs, Olson and Beasley (1995) each student uses learning styles as an individual's unique way when preparing, learning and remembering new and difficult information. Moreover, learning styles briefly consider the process of receipt and processing information (Felder \& Brent, 2005). Felder and Solomon (1994) included active-reflective, perceptive-intuitive, audio-visual, and sequential-global learning styles areas in the index of learning styles. Learning styles have been defined in various ways by many researchers. While Grasha (1996) defines learning styles as personal characteristics of a student which are effective on knowledge acquisition, interaction with friends and teachers and participation in learning experiences, Keefe (1979) defines learning styles as cognitive, emotional and psychological behaviors showing the learners' perceptions, interactions and responses in learning environments. Besides, Kolb (1984) defines his learning style model, which he bases on the premises of Piaget's cognitive development theory, as the learning style cycle formed by changing, internalizing, placing and resolving learning concepts in learning style model, and accepts learning as the conversion process of the production of knowledge to experience. Fleming (2001) and Felder and Brent's (2005) learning style definition refers to the processes of receiving-processing of any information, and concisely, can be expressed as receiving and organization of the information and the thoughts of individuals about information. Dunn, Griggs, Olson, and Beasley (1995) determined each student is using different and unique ways while preparing to learn a new and difficult information, learning and remembering as learning styles. 


\section{Method}

The research group has been selected randomly in accordance with criterion sampling which is a purposeful sampling method (Büyüköztürk, 2007). The sample of the study consisted of a total of 128 children including 64 girls and 64 boys from the age group of 5, and 3 different state kindergartens in Ankara.

Developed the index of learning styles, participants sought to identify the learning styles by providing two separate poles in learning styles choices. In this study, Index of Learning Styles for Children (ILSC) (Güneş, 2014) was used as a research instrument. The theoretical structure of ILSC belongs to Felder and Solomon's (1994) the Index of Learning Styles. The aim of this study is to examine the learning styles of preschool children and determine whether or not gender effects statistical difference on learning styles.

With regard to the ethical dimension of the research, ethics committee approval was obtained from the Ministry of Education for the children in the study, the school management and teachers were informed, the research results were presented to the requesting schools so as to "include only the results of their schools and keep confidential the names of the children in the survey". Besides this, information sheets were prepared for parents, permissions were obtained from their parents with voluntary participation forms for children, and the results of the children were shared with the requesting parents.

\section{Result and Discussion}

According to the results of the ILSC, children are generally active/intuitive/visual and sequential (analytic) learners. Descriptive statistics show that active learning with the ratio of $65 \%$, and also visual learning with the ratio of $67 \%$, has been identified as the most dominant learning styles. On the other hand, the intuitive-perceptual and sequential-global learning styles were used in a more balanced ratio were calculated. Children use the active and visual learning styles intensively, however, the perceptive/intuitive and global/sequential sub-dimensions of learning styles are very close to each other in the learning styles. It is known that children are visual, perceptual, and concrete activity (kinesthetic/tactile) learners (Kolb \& Kolb, 2005). Results of this study that examines the children active and visual learning styles are parallel to literature (Dunn and others 1995). However, Koyre (2000) said that in some cases, mind tends to use sequential learning style for achieving a whole from its parts. It can be evaluated that global/sequential learning styles used by children are in accord with Koyre's (2000) statement. When learning styles are examined according to the gender variable, it is understood that the girls more preferred intuitive and reflective learning styles than boys. It can be said that girls are active/intuitive/visual and sequential learners, boys are active/intuitive/visual and global learners. T-test results show that girls differ significantly than boys in reflective and sequential (analytic) learning styles. 